\title{
A generalized switching function-based SVM algorithm of single-phase three-leg converter with active power decoupling
}

\author{
Watcharin Srirattanawichaikul \\ Department of Electrical Engineering, Faculty of Engineering, Chiang Mai University, Thailand
}

\begin{tabular}{l}
\hline \hline Article Info \\
\hline Article history: \\
Received Apr 4, 2020 \\
Revised Jun 4, 2020 \\
Accepted Jun 19, 2020 \\
\hline
\end{tabular}

\section{Keywords:}

Active power decoupling Double-frequency ripple power Power conversion Single-phase three-leg Space vector modulation Voltage source converter

\begin{abstract}
In this paper, a generalized switching function-based space vector modulation (SVM) algorithm is presented and evaluated to minimize the dc voltage utilization and the ac utility grid current total harmonic distortion. This paper explores the control and modulation techniques of a single-phase three-leg converter with an active power decoupling method, where a generalized SVM algorithm is proposed and evaluated for easy implementation in a digital control platform. The active power decoupling method with the proposed converter can be achieved via dependent control and modulation techniques. The control method is separated into the ac active power control part and the dc power ripple control part, which can maintain a unity power factor at the ac utility grid and reduced the double-frequency ripple power effect on the dc-side. Simulation results validate the performance of the modulation algorithm and its control and demonstrate the feasibility of the proposed power converter, as well as the two mentioned operation modes of the power converter.
\end{abstract}

Copyright () 2020 Institute of Advanced Engineering and Science. All rights reserved.

\section{Corresponding Author:}

Watcharin Srirattanawichaikul,

Department of Electrical Engineering, Faculty of Engineering,

Chiang Mai University,

239 Huay Kaew Road, Muang District, Chiang Mai, 50200, Thailand.

Email: watcharin.s@eng.cmu.ac.th

\section{INTRODUCTION}

A single-phase voltage source converter is generalized use in the application of renewable energy sources and distributed generation systems such as solar photovoltaic (PV) systems, battery energy storage systems (BESS), ac-fed railway traction drive systems, and microgrid systems, etc. [1-4]. It is common knowledge that the traditional single-phase voltage source converter has some of the concerns with the standard power factor controller, in which the ac utility grid voltage and current are sinusoidal and unbalanced of the instantaneous power between ac-side power and dc-side power, from which a double-frequency ripple power will generate at the dc-side voltage [5-7]. The double frequency power ripple can be damaging to the system performance of the converter system. Mainly the double-frequency ripple power will cause degenerated lower efficiency and overheating when a solar PV system or a BESS is connected to the dc-side voltage [7-9]. In addition, the double-frequency ripple power will generate the beat phenomenon in the motor current of the ac-fed railway traction drive system, which causes power loss, torque pulsation, and audible noise $[10,11]$.

In recent times, numerous strategies of the passive power decoupling in the single-phase voltage source power converters, including modulation and control techniques, were conduct a survey as eliminating the double-frequency ripple power at the dc-link voltage [5-28]. The double-frequency ripple power has previously been accomplished using an active component to transfer from dc-link voltage to another energy storage component. In [5,6], an inclusive review of the methods for exterminating the double-frequency ripple power at the dc-link voltage, utilizing an additional active power circuit with different structures and 
control strategies can be found. There are lots of different designs for single-phase voltage source converters. The single-phase three-leg voltage source converter is composed of the two-phase legs known as the H-bridge converter. The third phase leg with a half-bridge converter, including an ac storage capacitor and the ac inductor are added, as reported in [11-15]. The voltage of the capacitor achieves excellent double-frequency ripple power performance. Furthermore, the third phase leg voltage of the power converter is higher than another phase legs. Consequently, the dc-link voltage requirement is significantly increased, which has an effect on the high voltage stress of the power switches.

The utilize of the single-phase three-leg voltage source converter with active power decoupling method as control, and modulation techniques have been carried out in literature [11, 13, 14]. In [11], the sinusoidal pulsewidth modulation (SPWM) of the three-leg power converter in the single-phase system was first presented. This modulation technique effectively overcomes the effects of dramatically increasing the dc voltage. Accordingly, the voltage stress of the switches is higher, and the size and weight of passive components are more massive. In [13], the pulse-width modulation control and the choice of the voltage reference and ac capacitance optimization for a three-phase legs power converter with an active power decoupling are investigated in detail. The control scheme can be minimized the voltage and current stresses of the power switches in which the size of the dc-link capacitor can be reduced by ten times. Nevertheless, the modulation technique has not been considered in the particulars. In [14], the modified SPWM techniques of the three-phase legs power converter with active power decoupling applied in the single-phase system are proposed. The modulation technique involves a zero-sequence voltage injection. As a result, the decrease of ac-side capacitance is improved, and the power converter efficiency is achieved.

In this paper, the generalized switching function-based space vector modulation algorithm is offered to the single-phase three-leg voltage source converter with an active power decoupling method, see Figure 1 (a). The chief advantages of the proposed converter system are improved dynamic performance, simplified control structure, unity power factor (UPF), and elimination of the double-frequency ripple power on the dc-link voltage side. Moreover, the proposed control system is suitable for bidirectional voltage source converters.

\section{CIRCUIT CONFIGURATION AND OPERATING PRINCIPLES}

\subsection{Proposed power converter configuration and system model}

Figure 1(a) illustrates the power circuit configuration of the single-phase three-leg voltage source converter with an active power decoupling method. This topology is two main parts: 1) The conventional $\mathrm{H}$-bridge power converter part is constituted of phase- $A$ and phase- $B$, which is controllable for the utility grid active power factor correction (PFC); 2) The proposed power circuit to eliminate the double-frequency ripple power in the converter system. The additional power switch is connected to phase- $C$ with two active power switches, and the ac-side of the capacitor and inductor are added.

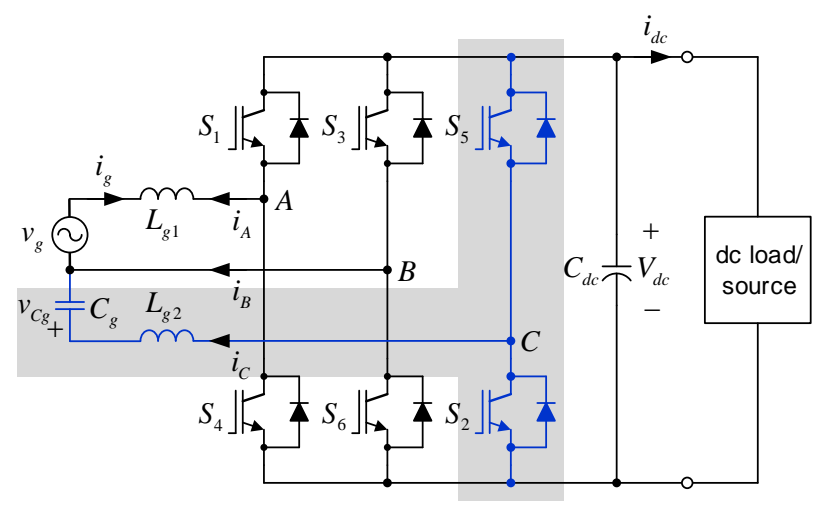

(a)

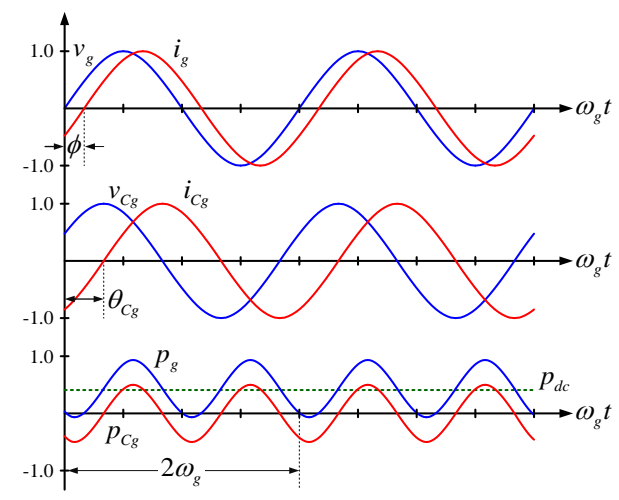

(b)

Figure 1. Single-phase three-leg voltage source converter with an active power decoupling method,

(a) power circuit, (b) principle of power ripple compensation

According to Figure 1(a), the average mathematical modeling of the power converter under the switching period can be described by 


$$
\begin{aligned}
& v_{L_{g 1}}=L_{g 1} \frac{d}{d t} i_{g}=v_{g}-v_{A B} \\
& v_{L_{g 2}}=L_{g 2} \frac{d}{d t} i_{C g}=v_{C B}-v_{C g}
\end{aligned}
$$

where $v_{g}$ is the ac utility grid voltage, $v_{C g}$ is the ac-side capacitor voltage, $i_{g}$ is the ac utility grid current, $i_{C g}$ is the ac-side capacitor current, $v_{A B}$ is the output converter voltage between phase- $A$ and phase- $B, v_{C B}$ is the output converter voltage between phase- $C$ and phase- $B, L_{g 1}$ is the filter inductor of the ac utility grid, and $L_{g 2}$ is the ac-side capacitance.

\subsection{Power decoupling principle of the power converter}

Figure 1(b) shows the idealized operating waveforms of the double-frequency ripple power cancellation by the ac-side capacitor. Assuming that the waveforms of the ac utility grid voltage and current are ideally sinusoidal, and not factoring the switching and conduction losses and filter inductance in the circuit, the voltage, and current waveforms can be defined as

$$
\begin{aligned}
& v_{g}=\sqrt{2} V_{g} \sin \left(\omega_{g} t\right) \\
& i_{g}=\sqrt{2} I_{g} \sin \left(\omega_{g} t+\phi\right)
\end{aligned}
$$

where $V_{g}$ and $I_{g}$ are the rms of the ac utility grid voltage and current, respectively, $\omega_{g}$ is the ac utility grid angular frequency, and $\phi$ is the power factor angle. In (2), the instantaneous ac power of the converter $p_{A B}$, which assume the instantaneous ac power grid, is expressed as

$$
p_{A B}=v_{g} i_{g}-L_{g 1} \frac{d i_{g}}{d t} i_{g}=V_{g} I_{g} \cos (\phi)+V_{g} I_{g} \sin \left(2 \omega_{g} t+\phi-\frac{\pi}{2}\right)-\omega_{g} L_{g 1} I_{g}^{2} \sin \left(2 \omega_{g} t+2 \phi\right)
$$

Therefore, the instantaneous ac power of the converter includes the average dc power $p_{A B, a v g}$ and the double ripple frequency of the instantaneous ac power of the converter $p_{A B, 2 \omega}$. Therefore, the instantaneous double-frequency ripple power of the converter is obtained

$$
p_{A B, 2 \omega}=P_{A B, 2 \omega} \sin \left(2 \omega_{g} t+\varphi_{A B}\right)
$$

In which the magnitude and the angle of the instantaneous double-frequency ripple power can be defined as

$$
\begin{aligned}
& P_{A B, 2 \omega}=\sqrt{\left(V_{g} I_{g}\right)^{2}+\left(\omega_{g} L_{g 1} I_{g}^{2}\right)^{2}-2 \omega_{g} L_{g 1} V_{g} I_{g}^{3} \sin (\phi)} \\
& \varphi_{A B}=\tan ^{-1}\left(-\frac{V_{g} I_{g} \cos (\phi)+\omega_{g} L_{g 1} I_{g}^{2} \sin (2 \phi)}{V_{g} I_{g} \sin (\phi)-\omega_{g} L_{g 1} I_{g}^{2} \cos (2 \phi)}\right)
\end{aligned}
$$

Similarly, the voltage and current of the ac-side capacitor are defined as

$$
\begin{aligned}
& v_{C_{g}}=\sqrt{2} V_{C g} \sin \left(\omega_{g} t+\theta_{C g}\right) \\
& i_{C_{g}}=C_{g} \frac{d}{d t} v_{C_{g}}=\sqrt{2} \omega_{g} C_{g} V_{C_{g}} \cos \left(\omega_{g} t+\theta_{C g}\right)
\end{aligned}
$$

where $V_{C g}$ is the rms of the ac-side capacitor voltage, $i_{C g}$ is the instantaneous of the ac-side capacitor current, $C_{g}$ is the ac-side capacitor, and $\theta_{C g}$ is the angle of the ac-side capacitor voltage. Therefore, the instantaneous power of the ac-side capacitor $p_{C B}$ is given as

$$
p_{C B}=v_{C g} i_{C g}-L_{g 2} \frac{d i_{C g}}{d t} i_{C g}=\frac{V_{C g}^{2}}{Z_{C B}} \sin \left(2 \omega_{g} t+2 \theta_{C g}\right)
$$

where $Z_{C B}=\frac{1}{\omega_{g} C_{g}}-\omega_{g} L_{g 2}$ 
The double-frequency ripple of the instantaneous ac power in (4) is a sinusoidal function, which results in an undesirable double-frequency ripple power on the dc-link voltage. However, the power ripple should be buffered at the decoupling circuit by the ac-side capacitor. Therefore, the relationship of the active power can be expressed as

$$
p_{d c}=p_{A B, a v g}+\left(p_{A B, 2 \omega}-p_{C B}\right)
$$

where $p_{d c}$ is the average dc power.

According to (4) and (7), the double-frequency ripple power of the instantaneous power can be compensated straight through the instantaneous power generated by the ac-side capacitor, which satisfied as $p_{C B}=p_{A B, 2 \omega}$. Consequently, the magnitude of voltage and current, and the phase angle of the ac-side capacitor should satisfy as

$$
V_{C g}=\sqrt{P_{A B, 2 \omega} Z_{C B}}, \quad I_{C g}=\frac{V_{C g}}{Z_{C B}}, \quad \theta_{C g}=\frac{\varphi_{A B}}{2}
$$

The double-frequency ripple power can be canceled by the ac-side capacitor, which is disappearing in the dc-side of the power converter. It can also see that the required dc-side capacitance for retaining constant dc-link voltage can be necessarily reduced. Figure 2 illustrates the phasor diagram of the proposed power converter. In the condition of the UPF, the ac-side capacitor phase angle can be described as:

- When the inverting operating mode, the active power flows into the dc-side and flows out of the ac utility grid: The ac utility grid current is out of phase $(\phi=\pi)$, and the ac-side capacitor phase angle $\theta_{C g}$ is $\pi / 4$.

- When the rectifying operating mode, the active power flows out of the ac utility grid and flows into the dc-side: The ac utility grid current is in phase $(\phi=0)$, and the ac-side capacitor phase angle $\theta_{C g}$ is $-\pi / 4$.

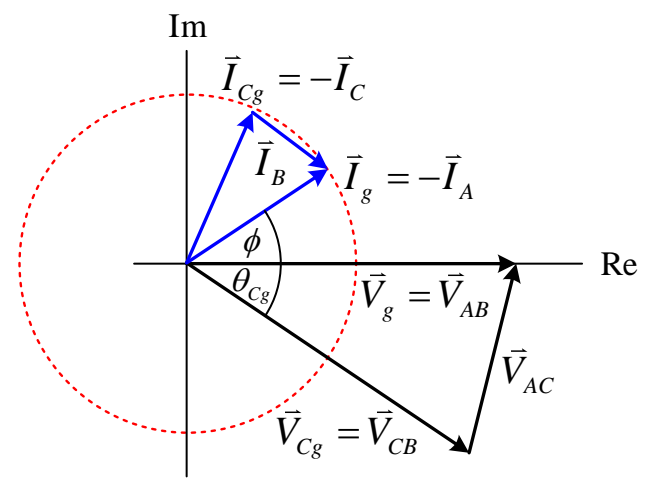

Figure 2. Phasor diagram for the proposed power converter

\section{CONTROL SYSTEM}

To improved the effectiveness and feasibility of the proposed SVM technique for the power converter, a control strategy is applied to the proposed power converter. Figure 3 illustrates the details of the proposed control system. It should be pointed out that the power converter system controller composed of the ac active power controller part and the dc ripple power controller part. The representation of the control system for the power converter is presented in this section.

\subsection{AC active power controller}

In the upper part, see Figure 3, the ac active power control part is similar to the conventional grid current control in the H-bridge converter. The external dc-link voltage loop controller $G_{P I, V d c}$ generates the ac grid current amplitude for regulating the dc-link voltage to follow the voltage command. At that time, the internal grid current loop controller $G_{P R, I g}$ generates the reference voltage of the converter between phase- $A$ and phase- $B$ for regulating the ac utility grid current to track ac current command. The dc-link voltage is maintained at a dc voltage command by using a proportional-integral (PI) controller which offers the reference value of the ac utility grid current command, as follows 


$$
G_{P I, V_{d c}}(s)=k_{P, V_{d c}}+\frac{k_{I, V_{d c}}}{s}
$$

where $k_{P, V d c}$ and $k_{I, V d c}$ are the proportional and integral gains, respectively, at the dc-link voltage controller.

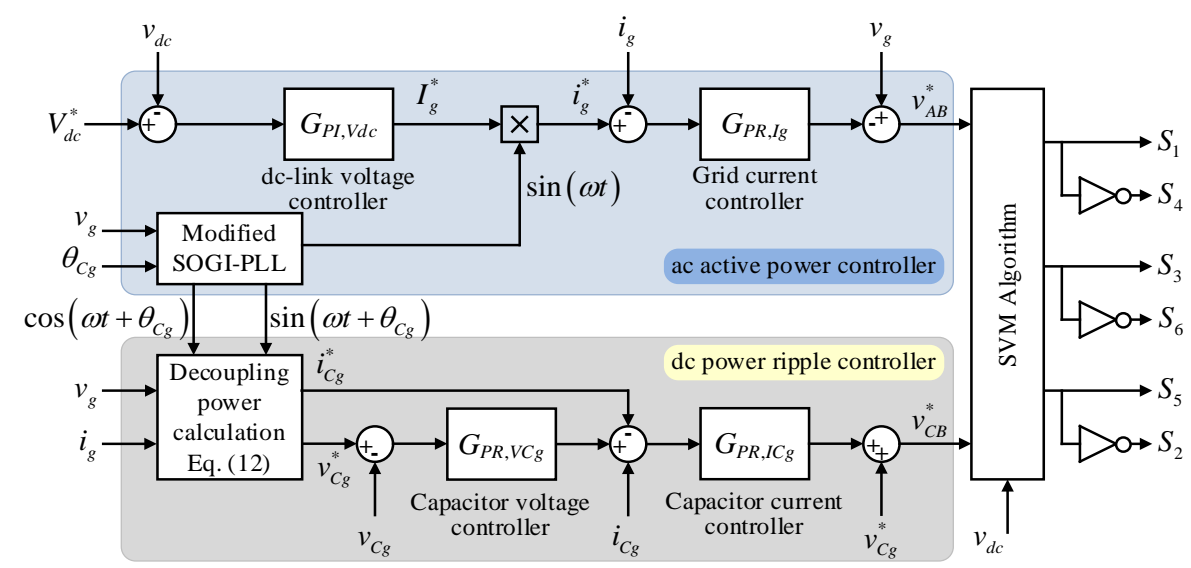

Figure 3. The proposed system controller of the single-phase three-leg voltage source converter with an active power decoupling method

To achieve the UPF condition and low total harmonic distortion (THD) of the ac utility grid current, the instantaneous current command is synchronized with the ac utility grid voltage utilizing a phase-locked loop (PLL) scheme. The system controller is modified the second-order generalized integrator PLL (SOGI-PLL) for the proposed power converter. It has proven to be robust against harmonics and voltage distortion [29, 30]. The command of the dc-link voltage controller is taken as the amplitude of the ac utility grid current. Multiplied by the ac utility grid voltage, it is utilized as the command for the inner-loop current control. A proportional-resonant (PR) controller of the ac utility current command can be expressed as

$$
G_{P R, I_{g}}(s)=k_{P, I_{g}}+\frac{2 \omega_{c} k_{R, I_{g}} s}{s^{2}+2 \omega_{c} s+\omega_{g}^{2}}
$$

where $k_{P, I g}$ and $k_{R, I g}$ are the proportional and resonant gains, respectively, at the ac utility grid current PR controller and $\omega_{c}$ is the cutoff bandwidth.

\subsection{DC ripple power controller}

The lower part of Figure 3 is the dc power ripple control scheme, which consists of the ac-side capacitor current and voltage controllers. The objective of this controller is to reduce the twice harmonic ripple in the dc-side of the power converter. For the ripple power control, the commands for the ac-side capacitor current and voltage are calculated by the decoupling power calculation block diagram according to the measured ac utility grid voltage and current. These commands have fluctuated at twice harmonic ripple the ac utility grid frequency to recompense for the power fluctuation. The commands for the ac-side capacitor voltage and current, $v_{C g}^{*}$ and $i_{C g}^{*}$, are calculated according to (9), given by

$$
\begin{aligned}
& v_{C g}^{*}=\sqrt{P_{A B, 2 \omega} Z_{C B}} \sin \left(\omega_{g} t+\theta_{C g}\right) \\
& i_{C g}^{*}=\frac{V_{C g}^{*}}{Z_{C B}} \cos \left(\omega_{g} t+\theta_{C g}\right)
\end{aligned}
$$

In (12), the ripple power compensating is offered by the controller, as illustrated in Figure 3. The ac-side capacitor voltage command is selected appropriately. To measure the amplitude of the ac-side capacitor voltage $v_{C g}$, and comparing with the ac-side capacitor voltage command $v_{C g}^{*}$, the outer loop can be a PR controller, expressed as

A generalized switching function-based SVM algorithm of single-phase ... (Watcharin Srirattanawichaikul) 


$$
G_{P R, V_{C g}}(s)=k_{P, V_{C g}}+\frac{2 \omega_{c} k_{R, V_{C}} s}{s^{2}+2 \omega_{c} s+\omega_{g}^{2}}
$$

where $k_{P, V C g}$ and $k_{R, V C g}$ are the proportional and resonant gains, respectively, at the ac capacitor voltage PR controller. For the inner loop, a PR controller, as shown in (14), is normally considered, as its primary function is to improve the performance of the converter system.

$$
G_{P R, I_{C g}}(s)=k_{P, I_{C g}}+\frac{2 \omega_{c} k_{R, I_{C g}} s}{s^{2}+2 \omega_{c} s+\omega_{g}^{2}}
$$

where $k_{P, I C g}$ and $k_{R, I C g}$ are the proportional and resonant gains, respectively, at the ac-side capacitor voltage PR controller. According to Figure 3, the converter voltage commands for successful power decoupling generated by the system controller can be obtained as

$$
\begin{aligned}
& v_{A B}^{*}=G_{P R, I_{g}}(s)\left(i_{g}^{*}-i_{g}\right)-v_{g} \\
& v_{C B}^{*}=G_{P R, I_{C g}}(s)\left(i_{C g}^{*}-i_{C g}\right)+v_{C g}^{*}
\end{aligned}
$$

Finally, the converter voltage commands $v_{A B}^{*}$ and $v_{C B}^{*}$ in (15) are designed according to the dynamic modeling of the power converter. The converter voltage commands are used by the proposed SVM algorithm to generate the gating signals for the proposed power converter.

\section{PROPOSED GENERALIZED SVM ALGORITHM}

In the following section, a generalized switching function-based SVM technique for a single-phase three-leg voltage source converter with an active power decoupling method is discussed. This algorithm is an enlargement of the two-voltage modulator inside the space vector diagram, in that the reference vector is situated. The reference vector is used to generate the switching sequence for the SVM, as explained in the later section. The generalized SVM algorithm is flexibility and generalization to the proposed power converter.

\subsection{Switching states}

A three legs power converter in the single-phase system can establish eight detached switching states. All the switching states of the proposed power converter are defined in Table 1, which are eight voltage vectors. The four voltage vectors, $\vec{V}_{1}, \vec{V}_{3}, \vec{V}_{4}$ and $\vec{V}_{6}$, produce the $V_{d c}\left(\vec{V}_{1}, \vec{V}_{3}, \vec{V}_{4}\right.$ and $\left.\vec{V}_{6}\right)$, the two vectors, $\vec{V}_{2}$ and $\vec{V}_{5}$, produce $\sqrt{2} V_{d c}$, and the two vectors are zero voltage $\left(\vec{V}_{0}\right.$ and $\left.\vec{V}_{7}\right)$ where the output voltages $V_{A B}$ and $V_{C B}$, in the event of the dc-link voltage income, the three different voltages, $V_{d c},-V_{d c}$, and 0 .

Table 1. Switching state definitions and the corresponding output voltages

\begin{tabular}{cccccc}
\hline \multicolumn{2}{c}{ Switching states } & Space vector definition & \multicolumn{2}{c}{ Output voltages } \\
$S_{1}$ & $S_{3}$ & $S_{5}$ & & $V_{A B}$ & $V_{C B}$ \\
\hline 0 & 0 & 0 & $\vec{V}_{0}=0$ & $V_{d c}$ & 0 \\
1 & 0 & 0 & $\vec{V}_{1}=V_{d c} e^{j 0}$ & $V_{d c}$ & $V_{d c}$ \\
1 & 0 & 1 & $\vec{V}_{2}=\sqrt{2} V_{d c} e^{j \frac{\pi}{4}}$ & 0 & $V_{d c}$ \\
0 & 0 & 1 & $\vec{V}_{3}=V_{d c} e^{j \frac{\pi}{2}}$ & $-V_{d c}$ & 0 \\
0 & 1 & 1 & $\vec{V}_{4}=V_{d c} e^{j \pi}$ & $-V_{d c}$ & $-V_{d c}$ \\
0 & 1 & 0 & $\vec{V}_{5}=\sqrt{2} V_{d c} e^{j \frac{5 \pi}{4}}$ & 0 & $-V_{d c}$ \\
1 & 1 & 0 & $\vec{V}_{6}=V_{d c} e^{j \frac{j \pi}{2}}$ & 0 & 0 \\
1 & 1 & 1 & $\vec{V}_{7}=0$ & & \\
\hline
\end{tabular}




\subsection{Vector representations}

The conventional SVM technique generally processes the information in the two-phase voltage reference frame coordinate. A similar procedure is applied in the proposed algorithm. The two-phase voltage reference frame supplied by the power converter will be replaced by the elliptical plane, as shown in Figure 3. A space vector diagram includes two zero vector lines on the center and six active vectors with six sectors (1)-(6) replaced by the space vector plane. The two-phase reference voltage in the space vector diagram is defined with the real axis and imagined axis. Accordingly, the reference voltage vector produced by the power converter can be obtained as

$$
\vec{v}_{r e f}^{*}=v_{A B}^{*}+j v_{C B}^{*}
$$

From the above equation, the two reference voltages on the space vector plane can be transformed to polar coordinates as

$$
\vec{v}_{r e f}^{*}=\left|\vec{v}_{r e f}^{*}\right| e^{j \theta_{s}^{*}}, \quad\left|\vec{v}_{r e f}^{*}\right|=\sqrt{v_{A B}^{*}+j v_{C B}^{* 2}}, \quad \theta_{s}^{*}=\tan ^{-1}\left(\frac{v_{C B}^{*}}{v_{A B}^{*}}\right)
$$

where $\vec{v}_{r e f}^{*}$ is the reference voltage vector, $v_{A B}^{*}$ is the reference output voltage between phase- $A$ and phase- $B$ of the power converter and $v_{C B}^{*}$ is the reference output voltage between phase- $C$ and phase- $B$ of the power converter, $\left|\vec{v}_{r e f}^{*}\right|$ is the amplitude of the reference voltage vector and $\theta_{s}^{*}$ is the reference angular displacement.

\subsection{Dwelling time and switching sequence for generalized switching function}

In the SVM approach, the purpose of the modulation algorithm is to approximate the reference voltage vector by a unification of the switching patterns. Assuming that the reference voltage vector is steady and the sampling period is sufficiently minimal, the sampled reference voltage vector with a sampling period is realized using the four adjacent voltage vectors with time duration as given by

$$
\begin{aligned}
& \vec{V}_{n, r e f}=\vec{V}_{0} \frac{t_{0}}{T_{s}}+\vec{V}_{n} \frac{t_{n}}{T_{s}}+\vec{V}_{n+1} \frac{t_{n+1}}{T_{s}}+\vec{V}_{7} \frac{t_{7}}{T_{s}}, \quad T_{s}=t_{0}+t_{n}+t_{n+1}+t_{7} \quad: n=1,2, \ldots, 6 \\
& \left|\vec{V}_{r e f}^{*}\right| e^{j \theta_{s}^{*}}=\frac{t_{n}}{T_{s}} V_{n} V_{d c} e^{j \theta_{s, n}^{*}}+\frac{t_{n+1}}{T_{s}} V_{n+1} V_{d c} e^{j \theta_{s, n+1}^{*}}
\end{aligned}
$$

where $\vec{V}_{n, \text { ref }}$ is the reference voltage vector, $\vec{V}_{0}, \vec{V}_{7}$ are the zero voltage vectors, $T_{s}$ is the switching period, $\vec{V}_{n}, \vec{V}_{n+1}$ are the output voltage vectors, $t_{0}, t_{7}$ are the time duration spent on the zero voltage vectors, $t_{n}, t_{n+1}$ are the switching time duration spent on the output voltage vectors, and $\theta_{s, n}^{*}, \theta_{s, n+1}^{*}$ are the angle of the voltage vectors. Referring to space vector diagram in Figure 4, the amounts in vector voltages for each sector are illustrated in Table 2. Therefore, the time durations solved by (19) can be arranged as

$$
t_{n}=\frac{\left|\vec{v}_{r e f}^{*}\right|}{V_{n} V_{d c}} T_{s} \frac{\sin \left(\theta_{s, n+1}^{*}-\theta_{s}^{*}\right)}{\sin \left(\theta_{s, n+1}^{*}-\theta_{s, n}^{*}\right)}, \quad t_{n+1}=\frac{\left|\vec{v}_{r e f}^{*}\right|}{V_{n} V_{d c}} T_{s} \frac{\sin \left(\theta_{s}^{*}-\theta_{s, n}^{*}\right)}{\sin \left(\theta_{s, n+1}^{*}-\theta_{s, n}^{*}\right)}, \quad t_{0}=t_{7}=\frac{T_{s}-t_{n}-t_{n+1}}{2}
$$

The spaces among the two voltage vectors in each sector are illustrated in Figure 4. The output voltage of the power converter can be signified by a rotating voltage vector with a clockwise direction for the rectifying mode and a counter-clockwise direction for the inverting mode. Table 3 illustrates the switching sequences for the proposed power converter.

According to this section, an SVM algorithm is proposed to minimize the output current ripple by applying the switching strategy. The block diagram of the proposed SVM algorithm is illustrated in Figure 5. The modulation process for the practical implementation can be divided into four parts: 1) voltage space vector calculation, 2) voltage and angle calculation, 3) dwelling time calculation, and 4) switching sequence selection to generated gating signals for the power converter. 


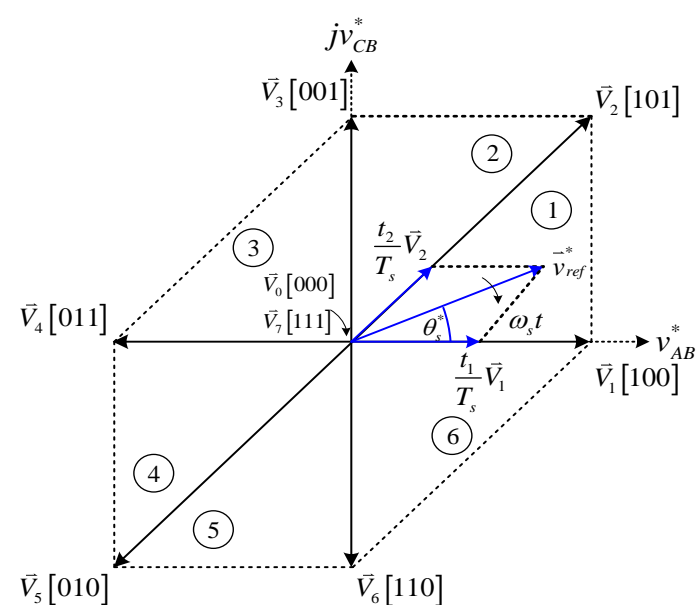

Figure 4. Space vector diagram of the proposed power converter in Figure 1(a)

Table 2. Amounts of the generalized SVM algorithm

\begin{tabular}{|c|c|c|c|c|c|c|}
\hline \multirow[t]{2}{*}{ Sector } & \multicolumn{2}{|c|}{ Voltage vectors } & \multicolumn{2}{|c|}{$\begin{array}{l}\text { The magnitude of } \\
\text { the voltage vector }\end{array}$} & \multicolumn{2}{|c|}{$\begin{array}{l}\text { The angle of } \\
\text { the voltage vector }\end{array}$} \\
\hline & $\vec{V}_{n}$ & $\vec{V}_{n+1}$ & $V_{n}$ & $V_{n+1}$ & $\theta_{s, n}$ & $\theta_{s, n+1}$ \\
\hline (6) & $\vec{V}_{1}[100]$ & $\vec{V}_{6}[110]$ & 1 & $\sqrt{2}$ & 0 & $\frac{3 \pi}{2}$ \\
\hline (5) & $\vec{V}_{5}[010]$ & $\vec{V}_{6}[110]$ & 1 & $\sqrt{2}$ & $\frac{5 \pi}{4}$ & $\frac{3 \pi}{2}$ \\
\hline (4) & $\vec{V}_{5}[010]$ & $\vec{V}_{4}[011]$ & 1 & 1 & $\frac{5 \pi}{4}$ & $\pi$ \\
\hline (3) & $\vec{V}_{3}[001]$ & $\vec{V}_{4}[011]$ & $\sqrt{2}$ & 1 & $\frac{\pi}{2}$ & $\pi$ \\
\hline (2) & $\vec{V}_{3}[001]$ & $\vec{V}_{2}[101]$ & $\sqrt{2}$ & 1 & $\frac{\pi}{2}$ & $\frac{\pi}{4}$ \\
\hline (1) & $\vec{V}_{1}[100]$ & $\vec{V}_{2}[101]$ & 1 & 1 & 0 & $\frac{\pi}{4}$ \\
\hline
\end{tabular}

Table 3. Switching sequences of the generalized SVM algorithm

\begin{tabular}{ccc}
\hline Sector & Basic voltage vector & Switching sequences \\
\hline (6) & $\vec{V}_{0}, \vec{V}_{1}, \vec{V}_{6}, \vec{V}_{7}$ & $000 \leftrightarrow 100 \leftrightarrow 110 \leftrightarrow 111$ \\
(5) & $\vec{V}_{0}, \vec{V}_{5}, \vec{V}_{6}, \vec{V}_{7}$ & $000 \leftrightarrow 010 \leftrightarrow 110 \leftrightarrow 111$ \\
(4) & $\vec{V}_{0}, \vec{V}_{5}, \vec{V}_{4}, \vec{V}_{7}$ & $000 \leftrightarrow 010 \leftrightarrow 011 \leftrightarrow 111$ \\
(3) & $\vec{V}_{0}, \vec{V}_{3}, \vec{V}_{4}, \vec{V}_{7}$ & $000 \leftrightarrow 001 \leftrightarrow 011 \leftrightarrow 111$ \\
(2) & $\vec{V}_{0}, \vec{V}_{3}, \vec{V}_{2}, \vec{V}_{7}$ & $000 \leftrightarrow 001 \leftrightarrow 101 \leftrightarrow 111$ \\
(1) & $\vec{V}_{0}, \vec{V}_{1}, \vec{V}_{2}, \vec{V}_{7}$ & $000 \leftrightarrow 100 \leftrightarrow 101 \leftrightarrow 111$ \\
\hline
\end{tabular}

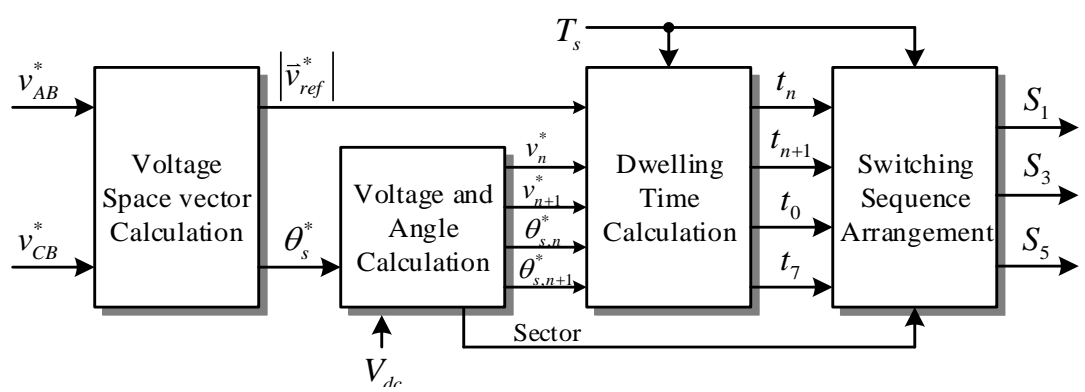

Figure 5. Block diagram of the proposed SVM algorithm 


\section{RESULTS AND DISCUSSION}

This generalized SVM algorithm in this paper is verified through simulation on a single-phase three-leg voltage source converter with an active power decoupling method, which has been simulated using the MATLAB/Simulink toolbox. The parameters of the power converter system for the following discussion are listed in Table 4, referring to Figure 1 (a). It should be mentioned that the dc capacitance in the converter system desires to absorb the switching ripple. Therefore, the dc-side capacitance is designed to be $600 \mu \mathrm{F}$, and the ac-side capacitance is calculated at $300 \mu \mathrm{F}$. The filter inductances $L_{g 1}, L_{g 2}$ are designed to be $2.4 \mathrm{mH}$ and $1.2 \mathrm{mH}$, respectively, which allowed the current ripple to be $20 \%$.

Table 4. Parameters of the proposed power converter

\begin{tabular}{lll}
\hline Parameter & Symbol & Value \\
\hline Rated active power & $P_{\text {rated }}$ & $10 \mathrm{~kW}$ \\
Grid voltage & $V_{g}$ & $230 \mathrm{~V}$ \\
Grid frequency & $f_{g}$ & $50 \mathrm{~Hz}$ \\
ac capacitor & $C_{g}$ & $300 \mu \mathrm{F}$ \\
dc-link capacitor & $C_{d c}$ & $600 \mu \mathrm{F}$ \\
dc-link voltage & $V_{d c}$ & $420 \mathrm{~V}$ \\
Inductance filter & $L_{g 1}$ & $2.4 \mathrm{mH}$ \\
& $L_{g 2}$ & $1.2 \mathrm{mH}$ \\
Deadtime & $t_{d}$ & $1.0 \mu \mathrm{s}$ \\
Sampling frequency & $f_{s}$ & $10 \mathrm{kHz}$ \\
Switching frequency & $f_{s w}$ & $10 \mathrm{kHz}$ \\
\hline
\end{tabular}

The performance of the proposed SVM algorithm for the single-phase three-leg voltage source converter with an active power decoupling method is effective in the inverting mode and rectifier mode at the full rated power of $10 \mathrm{~kW}$. Figure 6(a) illustrates the simulated waveforms of the voltage references of the controller system, which are applied to calculate in the SVM algorithm. The angular displacement and sectors from the relationship of two-phase reference voltages are illustrated in Figure 6(b). Figure 6(c) shows the timing for active and zero vectors. In Figure 6(d), the time duration for the voltage vectors basically explains the duty cycle waveforms in the on/off-state times of the selected switches during a sampling time.

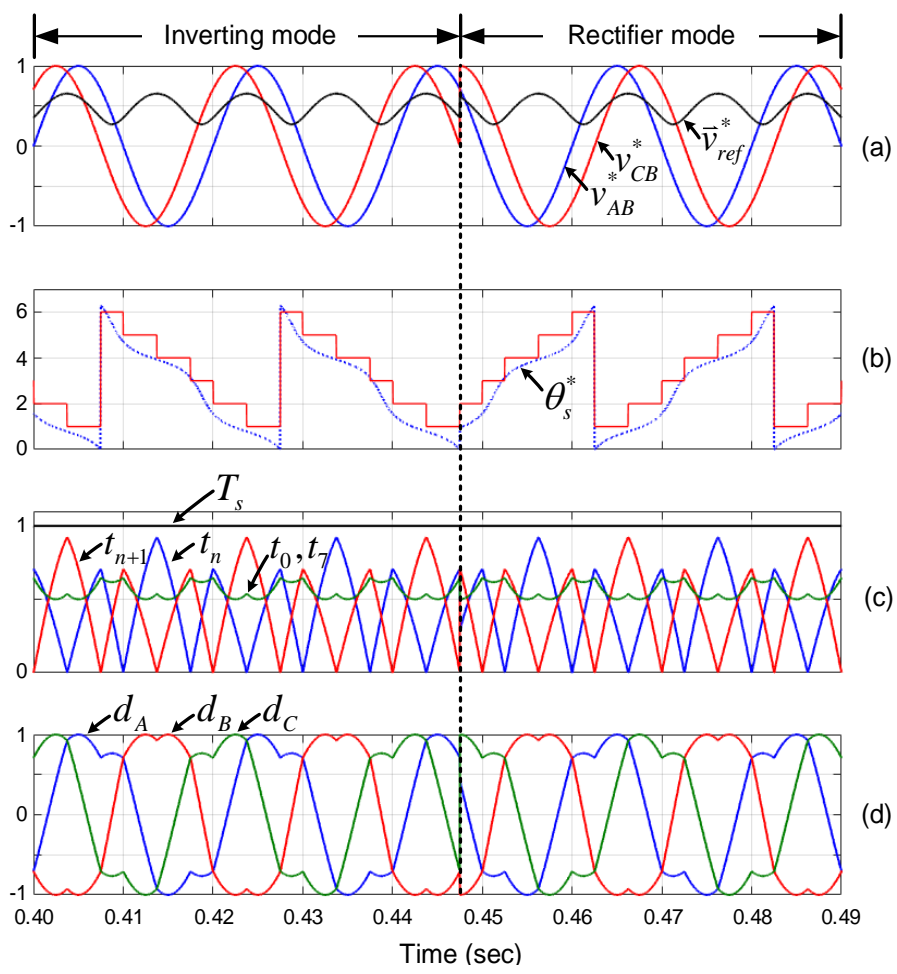

Figure 6. Modulating waveforms of the proposed SVM algorithm, (a) reference signals, (b) sector and angular displacement, (c) time durations, (d) duty cycles 
Figure 7 illustrates the steady-state waveforms of the power converter, with the full rated power, operating in the inverting mode and rectifier mode, respectively. As an inverting mode, the ac-side capacitor voltage, the voltage and current of the ac utility grid, and the dc-link voltage are displayed in Figure 7(a). It appears that the dc-link voltage is the smooth ripple voltage due to the ac storage capacitor. The ac power controller can regulate the ac utility grid current, and it is sinusoidal and out of phase with the ac utility grid voltage, which means the power flows from the dc-side into the ac-side. Moreover, the ac capacitor voltage is leading the grid voltage by the phase angle of $\pi / 4$ and is always constant. Figure 7(b) illustrates the output voltage waveforms of the power converter. The current waveforms of $i_{A}, i_{B}, i_{C}$, and $i_{N}$ a steady-state are represented in Figure 7(c).

As a steady operation in the rectifier mode, Figure 7(d) illustrates the steady-state voltage and current waveforms. The power converter maintains a unity power factor and a constant dc-link voltage. It should be noted that the ac utility grid voltage and current are in phase, and the dc-link voltage is maintained at $420 \mathrm{~V}$. The ac-side capacitor voltage is lagging the ac utility grid voltage by the phase angle of $-\pi / 4$. It is always constant by a control system. Figure 7(e) illustrates the output voltage waveforms of the power converter. The phase relationships of the output currents waveforms of $i_{A}, i_{B}, i_{C}$, and $i_{N}$ are represented in Figure 7(f).

Figure 8 illustrates the dynamic response of the power converter with the proposed SVM algorithm during a step-change in the input power. As shown in Figure 8(a), the input power follows a step change from full rated power to half rated power, and half rated power to full rated power is applied at $t=0.4 \mathrm{~s}$ and $t=0.7 \mathrm{~s}$, respectively. In Figure 8(b), the dc-link voltage controller regulated at its reference value of $420 \mathrm{~V}$, with a small overshoot during a step-change in the input power. The amplitude of the ac-side capacitor voltage decreases as the current magnitude decreases. During the step change, the current of ac utility grid change can vary approximately from $60 \mathrm{~A}$ to $30 \mathrm{~A}$. Considered the inverting operation mode, the power converter contains the dc-link voltage during all operating conditions. It can be seen that the waveforms of the output voltage are generated by the power converter, as given in Figure 8(c). During full and half rated power conditions, as shown in Figure 8(d), the grid active power changes from $10 \mathrm{~kW}$ to $5 \mathrm{~kW}$ and $5 \mathrm{~kW}$ to $10 \mathrm{~kW}$ during a step-change in the input power.

The dynamic response of the power converter with a linear change from inverting mode to rectifying mode is shown in Figure 8(e) to Figure 8(h). The active power command follows a linear pattern with changes from full rated power at inverting mode to the full rated power at rectifier mode $(10 \mathrm{~kW}$ to $-10 \mathrm{~kW})$, as shown in Figure 8(e). Figure 8(f) shows the steady-state voltage and current waveforms. The converter maintains the unity power factor, and the dc-link voltage is kept at $420 \mathrm{~V}$. It can be observed that the ac capacitor voltage is not constant, which varies with the grid current. The waveforms of the output voltage are generated by the power converter, as given in Figure $8(\mathrm{~g})$. The three currents are also shown in Figure $8(\mathrm{~h})$. It can be seen that the phase- $A$ current leads the phase- $C$ in the inverting mode and the phase relation reveres in the rectifier mode. The ac grid active power $P_{g}$ changes from approximately $10 \mathrm{~kW}$ to $-10 \mathrm{~kW}$ during the operation mode change.
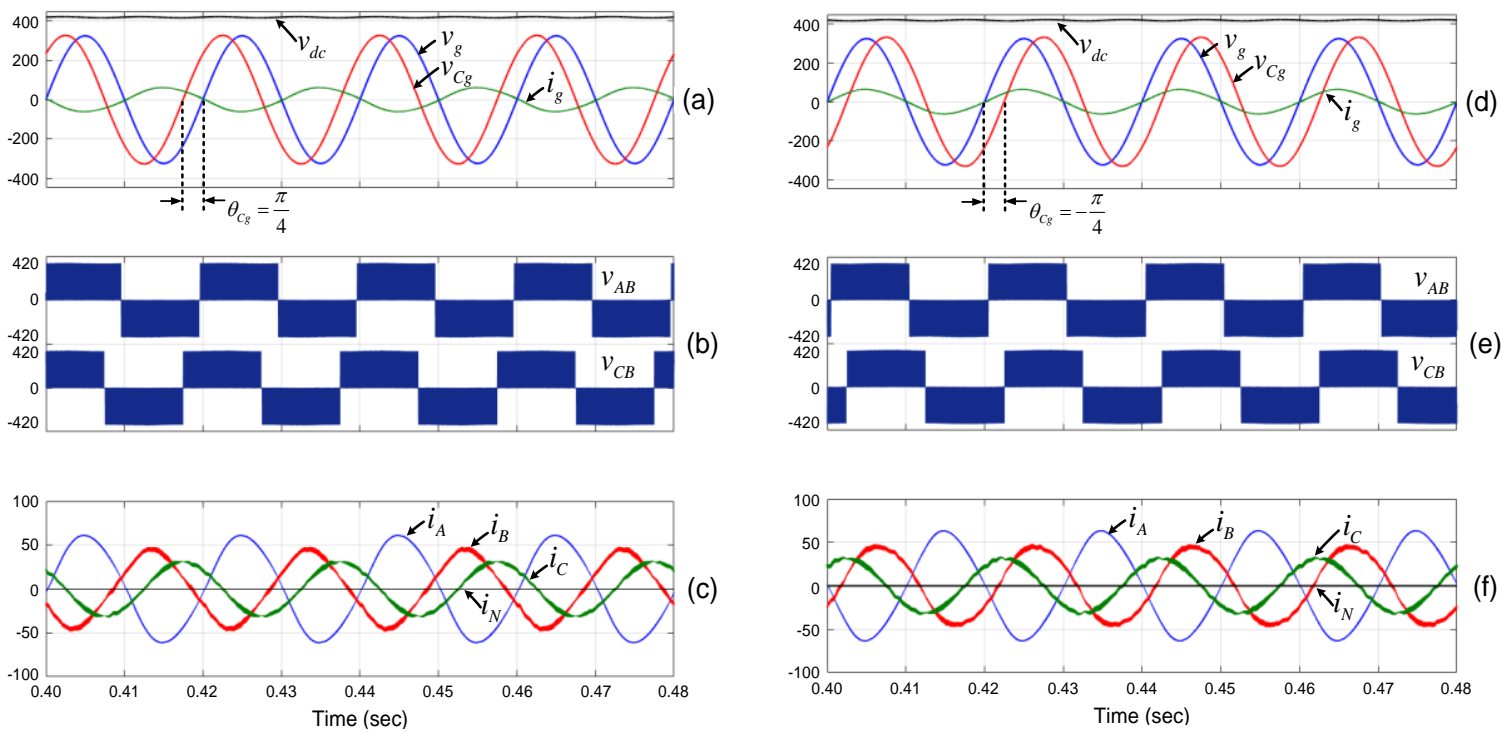

Figure 7. Steady-state waveforms when operating in the inverting mode and rectifier mode 

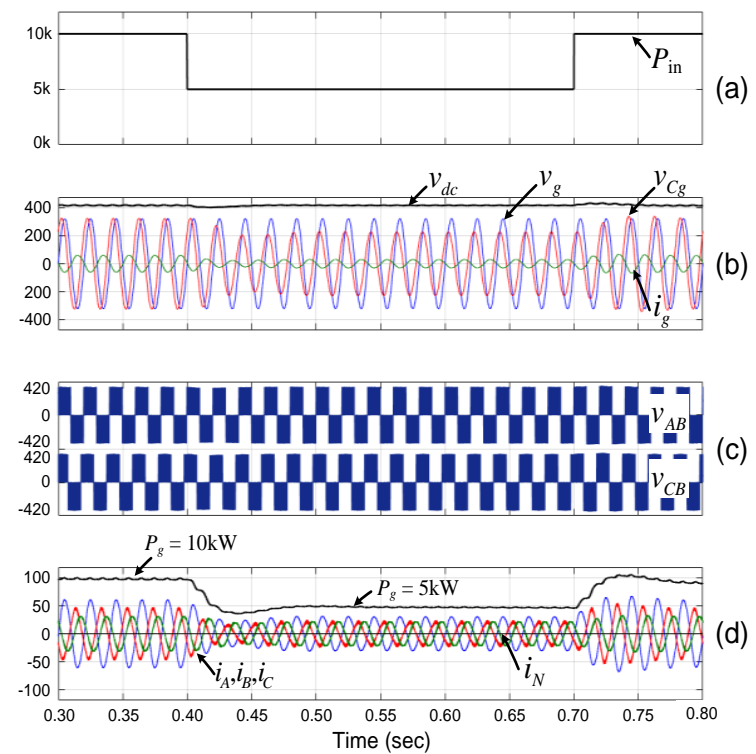

(a)

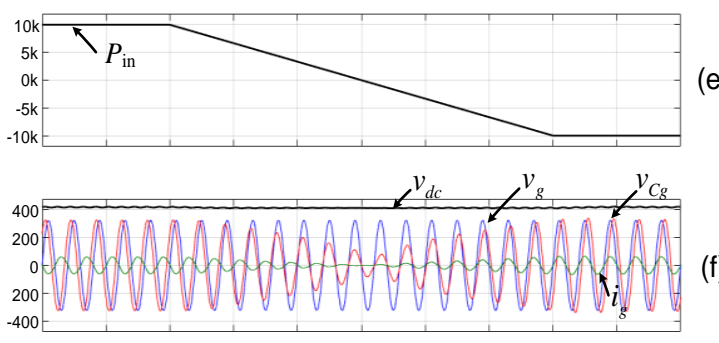

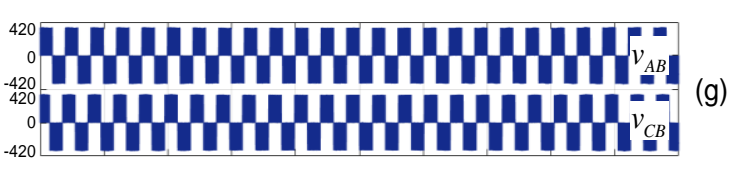

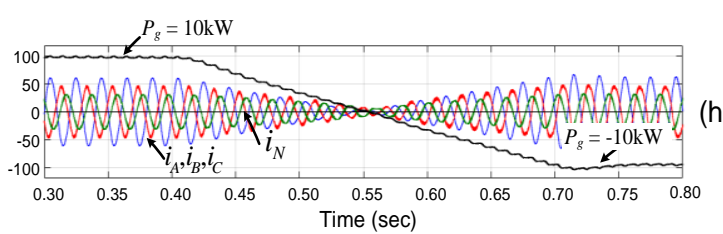

Figure 8. Dynamic waveforms during a step-change in the input power

Figure 9(a) and 9(b) show the dc-link voltage ripple at the rated power. It can be observed that the dc-link voltage is almost constant, with a peak-to-peak voltage ripple of exclusively $0.5 \%$ of the average dc voltage. Figure 9(b) gives the harmonic spectrum of the dc-link voltage, which shows the $100-\mathrm{Hz}$ component. The second-order component in the dc-link voltage is very low due to the proposed decoupling circuit and control. Nevertheless, the small second-order harmonic component motionless appears in the power variations because the power fluctuation compensation value has a small error as compared to the power converter fluctuation. The plots of total harmonic distortion of the ac utility grid current (THDi) computed from the simulation results for the proposed power converter are given in Figure 9(c) and 9(d). From the results as mentioned above, it can be seen that the variation of THDi for the proposed SVM algorithm has lower than the conventional sinusoidal PWM. This shows that, for a grid-connected converter and microgrid applications, this modulation algorithm gives an excellent performance in terms of THDi.
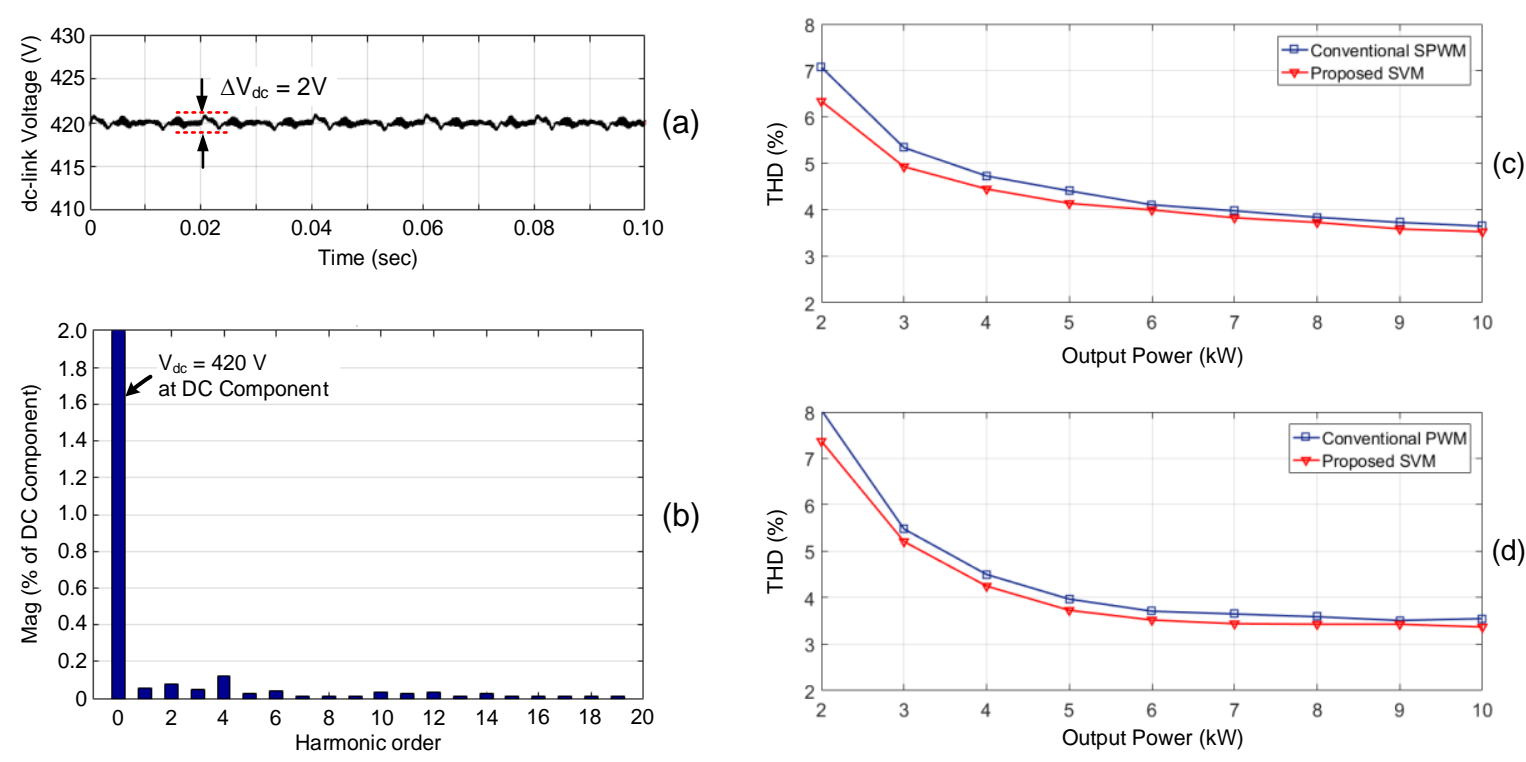

Figure 9. Total harmonic distortion analysis (a) waveform of the dc-link voltage,

(b) harmonic spectrum of the dc-link voltage at the rated power,

(c) output current THD at the inverting mode, (d) output current THD at the rectifier mode 


\section{CONCLUSION}

A generalized switching function-based SVM algorithm has been proposed for a single-phase three-leg voltage source converter with an active power decoupling method. The advantages of this technique are ease of digital control implementation and simplified algorithm. The simulation model verifies the effectiveness of the proposed modulation and control techniques. The simulation results confirm that the SVM algorithm and system controller would achieve a unity power factor and a stable dc-link voltage, and are able to handle the power ripple on the active power decoupling topology in the steady-state and dynamic conditions. This again confirms the effectiveness of the proposed modulation and control algorithm of the power converter.

\section{ACKNOWLEDGEMENTS}

The author gratefully acknowledges the financial support of the Office of the Higher Education Commission and the Thailand Research Fund for supporting this research under Grant No. MRG6180135. Furthermore, the author would like to thank the Faculty of Engineering, Chiang Mai University.

\section{REFERENCES}

[1] Y. Yang and F. Blaabjerg, "Overview of Single-phase Grid-connected Photovoltaic Systems," Electric Power Components and Systems, vol. 43, pp. 1352-1363, 2015.

[2] X. Wang, et al., "A Review of Power Electronics Based Microgrids," Journal of Power Electronics, vol. 12, no. 1, pp. 181-192, 2012.

[3] N. Eghtedarpour and E. Farjah, "Power Control and Management in a Hybrid AC/DC Microgrid," IEEE Transactions on Smart Grid, vol. 5, no. 3, pp. 1494-1505, 2014.

[4] G. Benysek, et al., "Power Electronic Systems as a Crucial Part of Smart Grid Infrastructure - A Survey," Bulletin of the Polish Academy of Sciences: Technical Sciences, vol. 59, no. 4, pp. 455-473, 2011.

[5] H. Zhang, et al., "Capacitance, dc Voltage Utilization, and Current Stress: Comparison of Double-Line Frequency Ripple Power Decoupling for Single-Phase Systems," IEEE Industrial Electronics Magazine, vol. 11, no. 3, pp. 37-49, 2017.

[6] Y. Sun, et al., "Review of Active Power Decoupling Topologies in Single-Phase Systems," IEEE Transactions on Power Electronics, vol. 31, no. 7, pp. 4778-4794, 2016.

[7] $\mathrm{H}$. Hu, et al., "A Review of Power Decoupling Techniques for Microinverters with Three Different Decoupling Capacitor Locations in PV Systems," IEEE Transactions on Power Electronics, vol. 28, no. 6, pp. 2711-2726, 2013.

[8] M. Pahlevani and P. Jain, "A Fast DC-bus Voltage Controller for Bidirectional Single-phase AC/DC Converters," IEEE Transactions on Power Electronics, vol. 30, no. 8, pp. 4526-4547, 2015.

[9] B. J. Pierquet and D. J. Perreault, "A Single-phase Photovoltaic Inverter Topology with a Series-connected Energy Buffer," IEEE Transactions on Power Electronics, vol. 28, no. 10, pp. 4603-4611, 2013.

[10] J. Klima, "Analytical Investigation of Influence of DC-link Voltage Ripple on PWM VSI fed Induction Motor Drive," in Proc. IEEE Conference on Industrial Electronics and Applications, pp. 1-7, 2006.

[11] H. Li, et al., "Active Power Decoupling for High-Power Single-phase PWM Rectifiers," IEEE Transaction on Power Electronics, vol. 28, no. 3, pp. 1308-1319, 2013.

[12] R. Chen, et al., "A Solid State Variable Capacitor with Minimum Capacitor," IEEE Transaction on Power Electronics, vol. 32, no. 7, pp. 5035-5044, 2017.

[13] R. Chen, et al., "DC Capacitor-less Inverter for Single Phase Power Conversion with Minimum Voltage and Current Stress," IEEE Transaction on Power Electronics, vol. 30, no. 10, pp. 5499-5507, 2015.

[14] H. Wu, et al., "Control and Modulation of Bidirectional Single-phase AC-DC Three-phase-leg SPWM converters with Active Power Decoupling and Minimal Storage Capacitance," IEEE Transaction on Power Electronics, vol. 31, no. 6, pp. 4226-4240, 2016.

[15] B. Ge, et al., "An Active Filter Method to Eliminate DC-Side Low-Frequency Power for a Single-Phase Quasi-ZSource Inverter," IEEE Transaction on Industrial Electronics, vol. 63, no. 8, pp. 4838-4848, 2016.

[16] J. You, et al., "An Active Power Decoupling Method for Single Phase DC/AC DAB Converters," IEEE Access, vol. 7, pp. 12964-12972, 2019.

[17] M. Su, et al., "Active Power Decoupling and Controlling for Single-phase FACTS Device," Journal of Engineering, vol. 2019, no. 16, pp. 1333-1337, 2019.

[18] W. Yao, et al., "Improved Power Decoupling Scheme for a Single-Phase Grid-Connected Differential Inverter With Realistic Mismatch in Storage Capacitances," IEEE Transaction on Power Electronics, vol. 32, no. 1, pp. 186-199, 2017.

[19] Y. Liu, et al., “A Single Phase AC/DC/AC Converter With Unified Ripple Power Decoupling,” IEEE Transaction on Power Electronics, vol. 33, no. 4, pp. 3204-3217, 2018.

[20] H. Watanabe, et al., "Development of DC to Single-Phase AC Voltage Source Inverter With Active Power Decoupling Based on Flying Capacitor DC/DC Converter," IEEE Transaction on Power Electronics, vol. 33, no. 6, pp. 4992-5004, 2018. 
[21] H. Yuan, et al., "On Nonlinear Control of Single-Phase Converters with Active Power Decoupling Function," IEEE Transaction on Power Electronics, vol. 34, no. 6, pp. 5903-5915, 2019.

[22] H. Sun, et al., "Automatic Power Decoupling Controller of Dependent Power Decoupling Circuit for Enhanced Transient Performance," IEEE Transaction on Industrial Electronics, vol. 66, no. 3, pp. 1820-1831, 2019.

[23] Y. Tang, et al., "A Dual Voltage Control Strategy for Single-Phase PWM Converters With Power Decoupling Function," IEEE Transaction on Power Electronics, vol. 30, no. 12, pp. 7060-7071, 2015.

[24] Y. Tang and F. Blaabjerg, "A Component-Minimized Single-Phase Active Power Decoupling Circuit with Reduced Current Stress to Semiconductor Switches," IEEE Transaction on Power Electronics, vol. 30, no. 6, pp. 2905-2910, 2015.

[25] K. Huang, et al., "Design of Power Decoupling Strategy for Single-Phase Grid-Connected Inverter Under Nonideal Power Grid," IEEE Transaction on Power Electronics, vol. 34, no. 3, pp. 2938-2955, 2019.

[26] Y. Tang, et al., "Decoupling of Fluctuating Power in Single-Phase Systems Through a Symmetrical Half-Bridge Circuit," IEEE Transaction on Power Electronics, vol. 30, no. 4, pp. 5499-5507, 2015.

[27] Z. Qin, et al., "Benchmark of AC and DC Active Power Decoupling Circuits for Second-Order Harmonic Mitigation in Kilowatt-Scale Single-Phase Inverters," IEEE Journal of Emerging and Selected Topics in Power Electronics, vol. 4, no. 1, pp. 15-25, 2016.

[28] M. Qiu, et al., "Active Power Decoupling Design of a Single-Phase AC-DC Converter," Electronics, vol. 8, pp. 1-18, 2019.

[29] F. Xiao, et al., "A Frequency-fixed SOGI-based PLL for Single-phase Grid-connected Converters," IEEE Transaction on Power Electronics, vol. 32, no. 3, pp. 1713-1719, 2017.

[30] C. Zhang, et al., "A Grid Synchronization PLL Method Based on Mixed Second- and Third-Order Generalized Integrator for DC Offset Elimination and Frequency Adaptability," IEEE Journal of Emerging and Selected Topics in Power Electronics, vol. 6, no. 3, pp. 1517-1526, 2018.

\section{BIOGRAPHY OF AUTHOR}

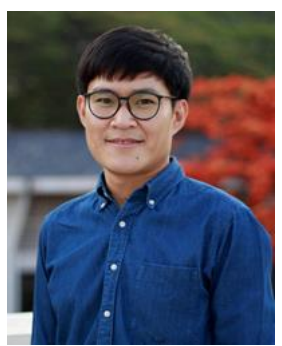

Watcharin Srirattanawichaikul was born in Chiang Mai, Thailand, in 1984. He received the B.Eng. degree in electrical engineering from the King Mongkut's Institute of Technology Ladkrabang, Bangkok, Thailand, in 2007, and the M.Eng. and Ph.D. degrees in electrical engineering from the Chiang Mai University, Chiang Mai, Thailand, in 2009 and 2015, respectively. He is currently a Lecturer with electrical engineering at Chiang Mai University, Chiang Mai, Thailand. His current research interests include power electronics for supporting the distributed generation and network systems, energy storage systems for renewable energy and electric vehicle, power quality, and microgrid. 